Revista Destaques Acadêmicos, Lajeado, v. 10, n. 4, 2018. ISSN 2176-3070

DOI: http://dx.doi.org/10.22410/issn.2176-3070.v10i4a2018.2014

http://www.univates.br/revistas

\title{
REVISÃO: AVALIAÇÃO DOS EFEITOS DO GLIFOSATO NO ECOSSISTEMA AGRÍCOLA E SUA TOXICIDADE PARA A SAÚDE HUMANA
}

\author{
Peterson Haas ${ }^{1}$, Lucélia Hoehne², Daniel Kuhn ${ }^{3}$
}

\begin{abstract}
Resumo: As ervas consideradas invasoras acarretam em $34 \%$ a redução da produtividade rural, por meio da competição por recursos presentes no solo, espaço físico e, inclusive, luminosidade. Portanto, a utilização de técnicas com o intuito de realizar o controle agrícola se torna necessária, seja por meio de práticas manuais e mecânicas ou através da aplicação de herbicidas, em que cerca de $60 \%$ do comércio mundial desses são à base de glifosato. No entanto, existem efeitos colaterais devido ao uso desses produtos. Dessa forma, o objetivo deste trabalho é fazer uma revisão sobre os efeitos do glifosato em relação ao ecossistema e à fisiologia vegetal, além de expor seus malefícios à saúde humana. Como resultados, verificou-se que o princípio-ativo é um agente não seletivo, pós-emergente e sistêmico e sua eficiência é atribuída devido ao seu mecanismo de ação que inibe a enzima 5-enolpiruvilshikimate-3-fosfato sintase, uma molécula essencial para a síntese de metabólitos secundários na via do ácido chiquímico. Embora sereshumanos e demais animais, em geral, não produzem os metabólitos secundários da via do ácido chiquímico, não se atribui toxicidade aguda ao glifosato. Contudo, verifica-se que, em virtude do aumento da resistência de ervas ao agente, eleva-se a dosagem de aplicação, propiciando biocumulação no solo e na própria cultura vegetal que o ser humano ingere posteriormente, absorvendo o contaminante. Portanto, observa-se que a atual legislação brasileira deve intervir através de trâmites que determinem doses máximas do glifosato em lavouras, estando em consonância com os limites de ingestão diária do composto de modo a reduzir os efeitos do glifosato na saúde humana e no ecossistema.
\end{abstract}

Palavras-chave: Glifosato, Controle Agrícola, Resistência de Ervas, Toxicidade.

1 Bolsista de Iniciação Científica Júnior, na Universidade do Vale do Taquari - Univates, Lajeado/RS, peterson.haas@gmail.com.

2 Professora e Doutora em Química, na Universidade do Vale do Taquari - Univates, Lajeado/ RS, luceliah@univates.br.

3 Mestrado em Biotecnologia, na Universidade do Vale do Taquari - Univates, Lajeado/RS, danielkuhn@universo.univates.br. 


\section{INTRODUÇÃO}

A ocupação de ervas na agricultura influencia o crescimento e o desenvolvimento das raízes do cultivo, uma vez que ocorre a competição por espaço, luz, água e nutrientes do solo, o que acarreta em baixo rendimento agrícola (WILSON, 1988; CLEMENTS, WEAVER, HANSON, 1929; RIZZARDI, 2001). Estima-se que práticas manuais e mecânicas de remoção das mesmas e a aplicação de herbicidas têm sido os métodos mais eficazes de controle de ervas (GRIEPENTROG e DEDOUSIS, 2010; ZIMDAHL, 2007). Dessa forma, a utilização destes compostos foi fundamental para a criação do sistema de plantio direto (SPD), implicando na eficácia da produção, visto que inibem o desenvolvimento de ervas específicas (seletivo) ou em geral (não-seletivo).

As classificações para esses agroquímicos são variadas, devido aos diferentes mecanismos de ação, grupos químicos, formulação, resistência do vegetal, seletividade e índices toxicológicos. Contudo, verifica-se que os inibidores mais comercializados mundialmente são à base de glifosato [N-(fosfonometil)glicina], um princípio-ativo não-seletivo, pós-emergente e sistêmico (JUNIOR \& SANTOS, 2002). Embora o mecanismo de ação do composto não atinja diretamente o organismo humano - tal fator que ocasiona baixa toxicidade ao mesmo -, há evidências de efeitos ambientais, o que implica em contaminação do solo e de lençóis freáticos e elevada dosagem do princípio-ativo nas produções agrícolas a partir do aumento da resistência de determinadas culturas. Posteriormente, o glifosato pode ser ingerido após ser absorvido pela cultura, acumulando-se e ultrapassando o grau de toxicidade permitido pela legislação (JUNIOR \& SANTOS, 2002)

Portanto, o objetivo deste artigo de revisão é avaliar os efeitos do glifosato em relação ao ecossistema e à fisiologia vegetal, além de expor seus malefícios à saúde humana.

\section{MECANISMO DE AÇÃO DO GLIFOSATO NAS PLANTAS}

O glifosato (Figura 1) é pulverizado nos ambientes agrícolas e absorvido pela planta através das folhas, translocando-se pelo floema para todas as suas partes até se depositar nas regiões meristemáticas responsáveis pelo crescimento vegetal (JUNIOR \& SANTOS, 2002). O herbicida age, então, nos vários sistemas enzimáticos, inibindo, especificamente, a enzima 5-enolpiruvilshikimate3-fosfato sintase (EPSPs), que atua fundamentalmente na via do ácido chiquímico. Visto que esse é precursor de importantes metabólitos secundários da planta, através da inibição dessa enzima o glifosato interrompe a produção desses compostos, acarretando em um desequilíbrio metabólico (YAMADA \& CASTRO, 2007). 
Figura 1. Fórmula Estrutural do Glifosato

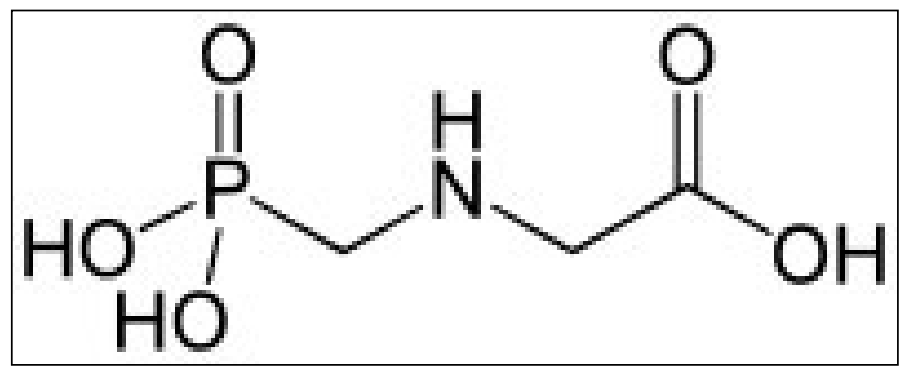

Dada a não-seletividade do agente, as enzimas EPSPs de plantas, fungos e da maioria de bactérias isoladas e caracterizadas são inibidas pelo mesmo, portanto, utilizam-se técnicas que impedem a ação contra culturas agrícolas, como a soja e o milho, por exemplo (NETTO, 2017). Dessa forma, cultivos transgênicos são empregados, os quais garantem resistência ao composto através de técnicas de DNA recombinante (SIQUEIRA et al., 2004). Assim, bactérias que superproduzem essa enzima possuem um código genético que permite a elas se desenvolverem sob altas concentrações do glifosato, portanto a transferência de genes de determinadas microorganismos à cultura vegetal confere tolerância a mesma diante da aplicação do herbicida (YAMADA \& CASTRO, 2007).

\section{EFEITOS DO GLIFOSATO AO ECOSSISTEMA AGRÍCOLA E À FISIOLOGIA VEGETAL}

Uma vez aplicado sobre o solo, as moléculas do herbicida podem ser degradadas ou adsorvidas. Tanto um processo quanto o outro pode acarretar na absorção do composto pelas plantas ou à lixiviação até lençóis freáticos e camadas sub-superficiais como um todo, ainda que a contaminação de águas subterrâneas seja pouco provável devido à rápida adsorção do poluente no solo (JUNIOR \& SANTOS, 2002). Em vista disso, dada a não seletividade do glifosato, este retorna ao solo após a absorção pelo vegetal, visto que, na maioria das vezes, não é metabolizado pela planta (TONI, SANTANA, ZAIA, 2006). Dessa forma, possibilita-se um aumento na disponibilidade biológica do composto no ambiente.

Portanto, a adsorção do glifosato em solos e minerais é fundamental para diminuir sua concentração, acelerar a degradação química do composto e retardar o movimento de lixiviação (TONI, SANTANA, ZAIA, 2006). Porém, diversos fatores interferem na eficiência do processo e na persistência do herbicida no solo, como temperatura, $\mathrm{pH}$, umidade, matéria orgânica, minerais e óxidos, etc. Além disso, os mecanismos principais para o processo são através da troca de ligantes com óxidos de ferro e alumínio e as pontes de hidrogênio formadas entre o composto e as substâncias ricas presentes no solo (FENG e 
THOMPSON, 1990). Portanto, observa-se uma variação no tempo de meia-vida $\left(t_{1 / 2}\right)$ do glifosato, dependendo das taxas de matéria orgânica e argila, nível de atividade microbiana e histórico de aplicações do composto (MORAES \& ROSSI, 2010; ARAÚJO et al, 2003). Logo, estudos apontaram $t_{1 / 2}$ igual a 19,2 dias para solos arenosos (CHEAH, KIRKWOOD, LUM, 1997), $\mathrm{t}_{1 / 2}$ igual a 8 a 9 dias para argissolos vermelho-amarelo (ARAÚJO et al, 2003) e $t_{1 / 2}$ igual a 12 dias para latossolos argilosos (ARAÚJO et al, 2003), .

Em vista disso, valores acentuados de meia-vida do herbicida no ambiente promovem um período maior de exposição com a biodiversidade presente em solos agrícolas (TONI, SANTANA, ZAIA, 2006). Uma das interferências é atribuída à transferência do composto por meio da plantaalvo para o cultivo. Essa passagem ocorre por meio do contato entre as raízes, influenciando na absorção do composto pela cultura e, consequentemente, na redução do sistema radicular. Segundo SANTOS et al. (2007), identificou-se que a época de aplicação do herbicida é um fator que pode acarretar efeitos adversos ao cultivo. Portanto, em intervalos de menos de 7 dias antes da semeadura, as concentrações de glifosato no solo ainda são altas, prejudicando o desenvolvimento radicular e inibindo a formação de uma densa microbiota nas raízes do vegetal. Dessa forma, verifica-se que a dessecação antecipada, ou seja, o controle químico realizado de 2 a 3 semanas antes da semeadura, proporciona melhores rendimentos.

Apesar do uso de herbicidas ser potente no combate às ervas, seu uso contribui para a susceptibilidade do cultivo diante de doenças vegetais (DUKE et al. 2006). Embora ainda hajam estudos insuficientes que abordem o processo físico-químico do glifosato responsável por aumentar a sensibilidade do vegetal, há significativas relações entre a atividade fungicida dos mesmos. Uma vez que diminui a microbiota e sistema radicular, a planta adquire baixa absorção de nutrientes (DALLMANN et al, 2010). Consequentemente, evidenciou-se que doses elevadas do agente reduzem o nível de fitoalexinas, um composto vegetal com propriedade antibacteriana, o que predispõe o vegetal a doenças. $\mathrm{O}$ aumento da susceptibilidade é predominantemente observado em culturas não-transgênicas, visto que a síntese de fitoalexinas é afetada em vegetais que possuem a via do ácido chiquímico interrompida.

Entretanto, a deposição de resíduos tóxicos no solo pode possibilitar a migração para águas superficiais por meio de lixiviação ou ação do vento. Em água, o tempo de meia-vida é mais curto em relação à persistência do composto no solo, visto que seus componentes são solúveis e podem se dispersar rapidamente (MORAES \& ROSSI, 2010). Sob águas superficiais, a degradação por microorganismos e adsorção por sedimentos corroboram para que o herbicida se dissipa de modo acelerado. A exemplo, estudos abordaram $\mathrm{t}_{1 / 2}$ de 7 a 21 dias (PATTERSON, 2007) e 7 a 14 dias (GIESY, DOBSON, SOLOMON, 2000). 
Dessa forma, a contaminação de rios e lagos afeta diretamente o ecossistema aquático do meio, acarretando mortalidade de peixes e aves que se alimentam na fauna aquática (SANCHES, 2003). Além disso, ocorre a poluição do meio, dificultando ou impedindo a atuação de processos de purificação de água para consumo humano, dada a dificuldade de separação do composto (JUNIOR \& SANTOS, 2002). Por tais circunstâncias, o glifosato e demais agroquímicos são considerados micropoluentes, devido ao seu caráter toxicológico no ecossistema (TONI, SANTANA, ZAIA, 2006).

Além da via de contaminação por contato direto, a dispersão aérea do composto implica em uma área de atuação maior. Dessa forma, a pulverização do composto pode ocasionar difusão para solos e recursos hídricos não-alvos. Ademais, o mesmo pode se disseminar para localidades domésticas quando estas se encontram próximas do espaço agrícola produtivo, vulnerabilizando o trabalhador por meio das vias de exposição dérmica e respiratória, além de contaminá-lo através do consumo de água quando este recurso provém de fontes hídricas dentro da área de abrangência do composto . Em adição, verificase que o glifosato pode promover ação sinérgica quando interagido com outras substâncias presentes no meio, acentuando seu potencial toxicológico para o ambiente e saúde humana (AMARAL, ROSA, SARCINELLI, 2013).

\section{RESISTÊNCIA DE ERVAS A HERBICIDAS}

A resistência de ervas por inibidores da enzima EPSPs deve-se a mutações do gene de plantas e bactérias que codifica a enzima EPSPs do sítioativo. Além disso, a seletividade natural de sementes geneticamente resistentes corrobora com a formação de linhagens pouco susceptíveis a ação do glifosato, beneficiando genótipos resistentes a se perpetuarem por gerações (VAN BRUGGEN, 2018). Tal circunstância deve-se a ação prolongada e de doses acentuadas do composto, acarretando efeitos deletérios no ambiente e à saúde do ser humano (JUNIOR \& SANTOS, 2002).

O aumento da resistência de ervas a inibidores de EPSPS é um fator que compromete o controle agrícola, uma vez que aumenta-se a dosagem de herbicidas e, consequentemente, os custos de produção e susceptibilidade do cultivo, possibilitando redução na produtividade agrícola (IKEDA, 2013). Dessa forma, verifica-se a importância de métodos alternativos de controle, tal como herbicidas com mecanismos de ação diferentes, rotação de culturas e/ou uso de pré-emergentes, os quais atuam diretamente na germinação de sementes de ervas (NETTO, 2017).

\section{EFEITOS TÓXICOS DO GLIFOSATO À SAÚDE HUMANA}

Visto que animais não possuem a via do ácido chiquímico, observa-se a índices baixos ou ausentes de efeitos agudos causados pelo glifosato, pois não acarreta desequilíbrio metabólito pela interrupção da atividade enzimática 
(JUNIOR \& SANTOS, 2002). Todavia, a presença de adjuvantes e conservantes na formulação dos herbicidas - os quais melhoram o desempenho do agente aumentando sua penetração no vegetal, emulsificação de compostos e dispersão no ambiente - torna tóxica a atividade sinérgica dessas propriedades (VAN BRUGGEN, 2018).

Além disso, verifica-se que, embora no Brasil não haja a existência de trâmites legais que estabelecem o limite do glifosato e qualquer herbicida em águas ou solo, a Agência de Proteção Ambiental dos Estados Unidos (US EPA) estabelece um limite de $700 \mu \mathrm{g} / \mathrm{L}$ de glifosato em água potável e dose diária aceitável do composto por massa corpórea equivale a 0,05 mg/ $\mathrm{kg}$ (BARCELÓ, 1993). Contudo, a dose estipulada do composto é muitas vezes ultrapassada, evidenciando alta exposição do herbicida no ambiente. Dessa forma, evidenciase que os efeitos crônicos dos herbicidas à base de glifosato estão relacionados com a elevada dosagem ingerida dos mesmos e acumuladas pelo organismo (VAN BRUGGEN, 2018).

Revela-se, portanto, irritação dérmica e ocular, com aumento de susceptibilidade de danos hepáticos e renais, doenças respiratórias e dermatológicas associadas à dispersão aérea do composto e à desregulação endócrina e do ciclo celular (OPAS, 1996; JUNIOR \& SANTOS, 2002). Todavia estudos já indicaram malefícios gastrointestinais em testes com ratos e porcos devido a contaminação dos alimentos e efeitos psicológicos devido à exposição contínua. Contudo, mais experimentações práticas se fazem necessárias para a comprovação efetiva desses resultados, visto que estudos ainda não demonstraram efeitos ao sangue, pâncreas e evidência de carcinogenicidade nos seres humanos (CARNEIRO, 2012).

De acordo com Fluegge (2016), há estreitas relações entre a intensificação do uso de glifosato com o surgimento e agravamento do Transtorno do Déficit de Atenção com Hiperatividade em municípios próximos à regiões agrícolas. Dada a propriedade de quelante mineral, o glifosato reduz a absorção do Manganês pelo vegetal, o qual proporciona a assimilação do Nitrogênio nas plantas. Dessa forma, diminui-se a nitrificação e aumenta-se a liberação de $\mathrm{N}_{2} \mathrm{O}$, tal emissão que é, posteriormente, inalada por indivíduos e afeta o quadro de doenças psicológicas

\section{CONSIDERAÇÕES FINAIS}

Dada a crescente necessidade de rendimento agrícola, tornam-se necessárias práticas de controle de ervas e pestes. Entretanto, o uso intenso de agroquímicos favorecidos pela baixa regulamentação e fiscalização legal impõem efeitos cumulativos no solo, recursos hídricos e na saúde humana. Ademais, a resistência vegetal e a introdução de culturas geneticamente modificadas submetem, cada vez mais, a elevadas doses desses compostos, 
acentuando o quadro de doenças crônicas proporcionadas pela inalação, contato e ingestão dos mesmos.

Verifica-se a importância de uma legislação nacional que regulamente a aplicação de herbicidas à base de glifosato conforme a taxa aceitável de ingestão diária dos mesmos, da mesma forma que o incentivo e a aplicação de técnicas alternativas se fundamentam para a eficácia da produção agrícola. Portanto, torna-se necessário reduzir a taxa de absorção do composto pelas plantas, tal processo que atenua a biocumulação do glifosato no organismo do ser humano e no ecossistema agrícola.

\section{REFERÊNCIAS}

AMARAL, E. I.; ROSA, A. C. S.; SARCINELLI, P. N. Estudo da exposição ambiental ao glifosato na área agrícola da serrinha do mendanha. Pesticidas: r. ecotoxicol. e meio ambiente, Curitiba, v. 23, p. 67-74, 2013.

ARAÚJO, A. S. F., et al. Biodegradação de glifosato em dois solos brasileiros. Pesticidas: R. Ecotoxicol e Meio Ambiente, Curitiba, v. 13, p. 157-164, 2003.

BARCELÓ, D. Environmental Protection Agency and other methods for the determination of priority pesticides and their transformation products in water. Journal of Chromatography, 643 (1993) 117-143.

CHEAH, U. B.; KIRKWOOD, R. C.; LUM, K. Y. Degradation of four commonly used pesticides in Malaysian agricultural soils. Journal of Agriculture and Food Chemistry, Washington, v. 46, p. 1217-1223, 1998.

CLEMENTS, F. E; WEAVER, J. E.; HANSON, H. C. (1929). Plant Competition: An Analysis of Community Functions. Carnegie Institute, Washington, D.C

DALLMANN C. M., et al. Impacto da aplicação de glifosato na microbiota do solo cultivado com soja geneticamente modificada. Revista Thema, p. 1-11, 2010.

DUKE, S. O.; CERDEIRA, A. L.; MATALLO, M. B. Uso de herbicidas e seus efeitos em doenças vegetais. Potafos Tecnologia para agricultura: informações agronômicas. Piracicaba, n. 115, 2006.

FENG, J. C.; THOMPSON, D. G. Fate of glyphosate in a Canadian forest watershed. 2: persistence in foliage and soils. Journal of Agriculture and Food Chemistry, Washington, v. 38, p. 1118-1125, 1990.

FLUEGGE, Keith; FLUEGGE, Kyle. Glyphosate Use Predicts Healthcare Utilization for ADHD in the Healthcare Cost and Utilization Project net (HCUPnet): A Two-Way Fixed-Effects Analysis. Pol. J. Environ. Stud., v. 25, n. 4, p. 1489-1503, 2016. 
GIESY, J. P.; DOBSON, S.; SOLOMON, K. R. Ecotoxicological risk assessment for roundup herbicide. Reviews of Environmental Contamination and Toxicology, New York, v.167, n.1, p.35-120, 2000.

GRIEPENTROG, H. W.; DEDOUSIS, A. P. Mechanical Weed Control. Soil Engineering, Springer, p. 171-179.

IKEDA, F. S. Resistência de plantas daninhas em soja resistente ao glifosato. Informe Agropecuário, Belo Horizonte, v. 34, n. 276, p. 0-00, 2013.

JUNIOR, O. P. A.; SANTOS, T. C. R. Glifosato: propriedades, toxicidade, usos e legislação. Química Nova, v. 25, n. 4, p. 589-593, 2002.

MORAES, P. V. D., ROSSI, P. Comportamento ambiental do glifosato. Scientia Agraria Paranaensis, v. 9, n. 3, p. 22-35, 2010.

NETTO, A. G. Crescimento e desenvolvimento, resistência múltipla aos herbicidas inibidores da EPSPS-ALS e alternativas em pós-emergência para controle de Amaranthus palmeri (S.) Wats. Universidade de São Paulo: Piracicaba, 2017.

ORGANIZAÇÃO PANAMERICANA DE SAÚDE. ORGANIZAÇÃO MUNDIAL DE SAÚDE (OPAS/OMS). Representação do Brasil. Manual de vigilância da saúde de populações Expostas a agrotóxicos, Brasília, 1996.

PATTERSON, M. Analysis of Risks to Endangered and Threatened Salmon and Steelhead. Environmental Field Branch, 2004.

RIZZARDI, M. A, et al. Competição por recursos do solo entre ervas daninhas e colônias. Ciência Rural, Santa Maria, v.31, n.4, p.707-714, 2001.

SANCHES, M. S., et al. Pesticidas e seus respectivos riscos associados à contaminação da água. Pesticidas: R. Ecotoxicol. e Meio Ambiente, Curitiba, v. 13, p. 53-58, 2003.

SANTOS, J. B. et al. Época de Dessecação Anterior à Semeadura sobre o

Desenvolvimento da Soja Resistente ao Glyphosate. Planta Daninha,Viçosa, v. 25, n.4, p. 869-875, 2007.

SIQUEIRA, J. O. et al. Interferências no agrossistema e riscos ambientais de culturas transgênicas tolerantes a herbicidas e protegidas contra insetos. Cadernos de Ciência e Tecnologia, Brasília, v. 21, n. 1, p. 11-81, 2004.

TONI, L. R. M.; SANTANA, H.; ZAIA, D. A. M. Adsorção de glifosato sobre solos e minerais. Química Nova, Londrina, v. 29, n. 4, p, 829-833, 2006.

VAN BRUGGEN, A. H . C. et al. Environmental and health effects of the herbicide glyphosate. Science of the Total Environment. v. 616-617, p. 255-268, 2018.

WILSON, J. B. Shoot Competition and Root Competition. Journal of Applied Ecology, v. 25 , n. 1 , p. $279-296,1988$. 
YAMADA, T.; CASTRO, P. Efeito do glifosato nas plantas: implicações fisiológicas e agronômicas. International Plant Nutrition Institute (IPNI). Encarte Técnico, n. 119, 2007.

ZIMDAHL, R. L. Invasive Plants. Fundamentals of Weed Science. ed. 3, p. 187-221, 2007. 